\title{
From the Editorial Board
}

DOI: $10.1134 / \mathrm{S} 1054661811060010$

This is second of two issues of the journal containing texts of the abstracts of the participants presented at the Tenth International Conference "Pattern Recognition and Image Analysis: New Information Technologies" (PRIA-10-2010) held in December 2010 at the St.-Petersburg Electrotechnical University "LETI" (St.-Petersburg, the Russian Federation), hosted by the National Committee of the Russian Academy of Sciences for Pattern Recognition and Image Analysis and the Institution of the Russian Academy of Sciences "Dorodnicyn Computing Centre of the RAS" (Moscow, the Russian Federation). The conference is supported by the Russian Foundation for Basic Research, the Foundation for Assistance to Small Innovative Enterprises, Information Research and Development, Ltd. (Moscow, the Russian Federation) and Biosignal, Ltd. (St.-Petersburg, The Russian Federation).

The theme of PRIA-10-2010 is "Knowledge Itself is Power", and the conference is a multi-track international forum-for discussions on recent advances in the field. Its scientific program included problems, related to the development, implementation, and application of information technologies for pattern recognition, image analysis and artificial intelligence, such as:

a) formulation, analysis, and solution of mathematical problems arising in the development and implementation of data transformation and estimation methods in pattern recognition, classification, and forecasting, with input data represented in the form of numerical and text arrays, expert data, signals, images, time-domain series, and random multidimensional fields;

b) image processing, analysis, recognition, understanding, and synthesis (including computer graphics, visualization, and virtual reality);

c) speech processing, analysis, recognition, and synthesis;

d) development, investigation, modification, and systematization of mathematical and computational methods providing the algorithmic foundation for information technologies;

e) development of methods for the computer-aided synthesis and testing information technologies; f) development of dedicated information technologies (for classes of problems and subject fields);

g) development and implementation of generalpurpose toolkits, databases, and knowledge bases to support information technologies for pattern recognition, image analysis, speech analysis and synthesis, and signal processing;

h) development, adaptation, and implementation of methods to handle off-standard, critical, and massscale tasks of pattern recognition and image, speech, and signal analysis and understanding.

The Conference was arranged in four sections:

1. Mathematical Methods in Pattern Recognition.

2. Representation, Processing, Analysis, and Understanding of Images.

3. Software and Hardware for Pattern Recognition and Image Analysis.

\section{Applied Problems.}

More than 200 scientists, researchers, PhD students and students from Germany, France, Italy, Spain, Brasilia, Turkey, Czech Republic, Finland, Taiwan, Belarus, Russia participated in the Conference. The scientific Program of PRIA-10-2010 included 209 papers (16 invited papers, 10 tutorials, 78 session papers, 104 posters, 1 exhibit).

Full texts of PRIA-10-2010 papers presented by the authors at the conference and recommended by the Program Committee will be published in the year of 2012 as special issues of the international journal "Pattern Recognition and Image Analysis. Advances in Mathematical Theory and Applications" (Pleiades Publishing Ltd./c/o INTERNATIONAL ACADEMIC PUBLISHING COMPANY "Nauka/Interperiodica", Moscow, distributed worldwide by SPRINGER).

\author{
Editor-in-Chief, \\ Conference Chairman of PRIA-10-2010, \\ Professor,
}

Full Member of the Russian Academy of Sciences Yu.I. Zhuravlev 